\title{
Solar Commercial Virtual Power Plant
}

\author{
Brecht Zwaenepoel \\ and Joannes I. Laveyne \\ and Lieven Vandevelde \\ Power-Link and \\ Electrical Energy Laboratory \\ Ghent University \\ Ghent, Belgium \\ Email: brecht.zwaenepoel@ugent.be
}

\author{
Tine L. Vandoorn \\ and Bart Meersman \\ Electrical Energy Laboratory \\ Ghent University \\ Ghent, Belgium \\ Email: tine.vandoorn@ugent.be
}

\author{
Greet Van Eetvelde \\ Environmental and spatial management \\ Ghent University \\ Ghent, Belgium
}

\begin{abstract}
Installed photo voltaic energy grew exponentially during the last decade. One of the driving forces was the often generous governmental support. In Belgium (Flanders) for example, investors could acquire green power certificates worth $€ 450 / M W h$ during several years. However, due to the large boom of solar plants and hence rising subsidy cost, governments are dropping this support (eg. $€ 450 / \mathrm{MWh}$ in 2009 to $€ 90 / \mathrm{MWh}$ in 2012 for Flanders). In this paper the authors investigate if solar energy can become more profitable if forces are joined in a Commercial Virtual Power Plant to sell the solar power on the wholesale market. The numbers are based on the Flemish region, however, the same procedure can be applied to other markets as well. It turned out that for existing installations the potential benefits are marginal due to the small share of the energy revenue compared to the subsidy revenue in the total income of a solar plant. However, lower subsidies and coupling with other production resources and (flexible) consumers promise to be more profitable, although this needs more investigation.
\end{abstract}

\section{Introduction: COMMERCIAl Virtual POWER Plants}

Commercial Virtual Power Plants (CVPP) cluster the output from different sources to commercialize the energy in a more profitable way. In its simplest form, it consists of installations of a company with a multisite metering contract. If combined in a multisite contract, these installations essentially form a CVPP. A more advanced version would offer (semi)real-time metering and sell the energy as one volume to a retailer. Because of aggregating these installations, the transactions are larger, thus better prices can be obtained. Due to their purely economical character, these VPPs are not geographically constrained. The only limitation is the operational area of the contracting energy retailer. A more advanced version of a CVPP is one which is capable of selling its energy on the stock market such as APX-ENDEX, Belpex DAM, Belpex CIM, EPEX Spot FR, EPEX Spot DE or EMCC. In most cases, this provides the participants a more interesting price than that obtained on the retail market. Although on average the price is better, the volatility is also much higher. This provides opportunities for flexible participants. During low prices on the stock market, Distributed Energy Resources (DER) with storage can curtail the production and consumers can buy cheap energy. During peak prices, this scenario is reversed. This system enables small consumers and DER to participate on the stock market. Due to the entrance fees [1], [2], minimum transaction volume [3], [4] and extra responsibilities, this is not possible for individual small or medium participants. Only the portfolio effect enables them to participate on the stock market as a group. In this paper, the authors will prove a CVPP with only Photo Voltaic (PV) capacity is not viable under present circumstances. However, due to the rapidly changing subsidy schemes and combined with DER, opportunities may arise.

In section II, an introduction to wholesale market operation is given. Section III elaborates on current solar power installations. Next, in section IV, CVPP operation is analyzed and section $\mathrm{V}$ presents the conclusions.

\section{WHOLESALE ENERGY TRADING}

\section{A. System balancing and energy trading}

In this section, the wholesale market operation is clarified. The numbers are based on the Belgian system, however, as Belgium, Germany, France and The Netherlands are coupled in one pentalateral market [5], their market situation is quite similar [6]. Trading of energy on the wholesale market comprises three levels: 1) Delivery 2) Trading 3) Clearing.

The trading system provides the economic coupling of buyers and sellers. The clearing system is providing an anonymous intermediary to guarantee contract settlement and the delivery platform ensures the needed capacity on the transmission grid. The delivery is discussed first because technical constrains can have a significant impact on the trading.

1) Delivery: The electricity purchased is physically transfered between Acces Responsible Parties (ARP) through the transmission grid. To provide the necessary balance between offtake and injection, ARPs need to nominate the expected transfer capacity the day before delivery (D-1) [7]. This requires the ARPs to estimate the consumption and/or the production on their access point to the transmission grid. This estimation needs to be submitted to the system operator on D-1 which uses this data to calculate the expected power flows in the transmission grid. ARPs need to enter an opposite nomination (positive and negative) in order to balance the power on a quarter-hourly basis with an accuracy of $0.1 \mathrm{MW}$. If those blocks do not match, the transfer is rejected [8]. As the nominations rely on predictions, there will always be some 
difference between the expected and the physical flows. As the system needs to be in balance at every moment [9], [10], the system operator needs to buy reserve capacity. To cover this cost, the transmission system operator will charge the ARPs according to their imbalances [11] on a quarter-hour basis. This fine encourages the ARPs to correctly estimate their positions in advance.

To deal with unforeseen circumstances, ARPs can exchange energy on the intraday hub [12]. This enables them to counteract circumstances like the breakdown of a production unit or a change in weather forecast. However, this instrument is strictly limited to only a few days per month to force ARPs to correctly predict their positions. For example, the Belgian system operator Elia enforces a 30 day ban if the intraday hub is used in more than three consecutive days or more than five days a month.

2) Trading: Next to the physical transfers, the energy is traded on the energy wholesale market. Suppliers and customers have different possibilities to trade the electricity. First of all, they have the possibility to trade "over the counter". The contract is made directly between the seller and the buyer. The risk is entirely with the two parties. The second option is to trade energy on exchange markets. This makes use of standard contracts which are traded on a stock exchange. In the exchange market there are two largely distinctive markets. The first is the futures market. Futures are contracts to deliver a certain quantity of electricity on a date in the future. This is an easy way of trading large quantities of base capacity, as these contracts are often concluded for months or years at a time. Pricing is often coupled to the oil price.

The second option is the spot market. On this market energy is traded close to the delivery time. The spot market has two separate parts: the Day Ahead Market (DAM) and the Continuous Intraday Market (CIM). Of the two the DAM is the most used. As the name suggest, the energy is traded the day before delivery. Sellers and buyers submit their supply and demand curves. Once a day these are matched via an auction process and a price for each trading hour of the following day is determined. This ensures an anonymous and transparent price fixing process. The CIM provides the parties to trade energy very close to the delivery time, up to a few minutes. As also physical acknowledgment of the grid operator is needed, this is a limited market. This is only used to settle large unbalance positions after gate closure on the DAM. As a result, only a few hours a day energy is traded. From the beginning of 2012, also the imbalance market is available. The possibility to trade on this market is also limited as this depends on the system state (net regulation volume). In this paper, those markets are omitted as the are limited usable to solar installations due to the inherently supply driven character of solar power.

3) Clearing: Clearing provides a structural way of mitigating credit risk. By clearing via a central counterparty, the clearing house becomes buyer to the original seller and seller to the original buyer. No contractual relationship is left between the original counterparties to a transaction. The clearing house manages payment and delivery risks via margining, based on the counterparties net trading position. This provides an anonymous intermediary to guarantee contract settlement and payment.

\section{B. Market analysis}

1) Markets: As already mentioned in section II-A, three markets can be utilized by a CVPP. The futures market, the spot day ahead and the spot intraday market. Each market has its advantages. The futures market is beneficial to mitigate risks as the prices are known from long before the actual delivery. For a solar CVPP, this is rather difficult as solar irradiation can not be predicted years or even months beforehand. The DAM is the second option, as the needed prediction horizon declines to only 12-36 hours. This is a more feasible prediction horizon, but still suffers from potential large deviations. The intraday market is the third option, but due to the limitations of the grid operators, its access is limited.

As a conclusion, the DAM is the most attractive way of trading energy for uncontrollable sources. Hence, the uncertainties of weather prediction need to be taken in account. In section IV-B, the comparison is made between $100 \%$ accurate prediction and with an uncertainty band of $\pm 10 \%$. Further research on prediction uncertainty is needed to analyze the effect of prediction error in more detail.

2) Trading prerequisites: To be allowed to trade on the market, the party need to become a participant of the stock exchange. The yearly admission fee for the Belpex for example is $€ 25.000$ for one year. Reductions are available for startups or indirect participants. The first year, a participant needs to pay an additional entrance fee of $€ 12.500$ to gain access to all market segments [2]. This costs need to be offset with the extra revenues and hence impose a minimum on the traded volume. Adittionally, the participants need to pay a variable operational fee with regard to all the contracts concluded on the stock market. Belpex for example charges $€ 0,10 / \mathrm{MWh}$ for DAM contracts and $€ 0,105 / \mathrm{MWh}$ for contracts concluded on the CIM. Different tariffs are available for startups.

3) Imbalance fee: Once nominations are confirmed and the market is settled, a participant can not change its position anymore (except for the limited possibilities of the CIM). As a result, the actual and nominated power can differ and result in an imbalance. As the grid operators rely on the forecast data to guarantee operational stability, they penalize offsets. The penalty is based on the direction (surplus or deficit) of the ARP and the system state. If the error of the ARP is "in the good direction", the fine will be lower than if the imbalance of the ARP is in the same direction as the system imbalance. The fine is also proportional to the mismatch.

4) Market resilience: As solar power is currently regarded as "negative consumption" by the ARPs, the PV volume is not visible on the market volumes. Offering this extra volume of energy on the market will trigger a price shift. The extra traded volume will shift the offer curve and hence influence the intersection with the demand curve. In [13], the sensitivity of the price to changed volume is investigated. It should however 
be noted that this study is also influenced by the market coupling of Belpex with the neighboring markets in France (EPEX Spot) and The Netherlands (APX-ENDEX). This enhances the utilization of the cross border capacity and simplifies cross border trading. As long as the Available Transfer Capacity (ATC) is sufficient, the three markets are coupled. From 9 november 2010 on, the trilateral market coupling has been further extended to the Central Western Europe (CWE) market comprising Germany, The Netherlands, Belgium, Luxembourg and France. This enhances the resilience of the market further. As a result, the relative small amount of solar energy will have no significant impact on the market price.

\section{SOLAR POWER ANALYSIS}

\section{A. Solar power in Flanders}

This paper elaborates on the Flemish situation concerning photovoltaic (PV) power, although the general conclusions are valid for any developed PV market. The Flemish situation offers an interesting case to test the feasibility of a SCVPP because in recent years, PV power in Flanders has known a rapid increase in total installed power as well as total energy yield. The main drivers for this exponential growth were the copious financial support offered by the Flemish regional government supplemented with tax breaks provided by the Belgian national government. Both these initiatives were motivated by the European 2020 goals. This went along with a drastic decrease of the cost of photovoltaic panels. From the start of the subsidizing program of the Flemish regional government in 2006, the yearly increase of installed PV power has reached levels as high as $488 \%$ in 2007 [14]. This unforeseen and overwhelming increase of total installed PV power confronted the Flemish regional government with a budget overrun and prompted the Flemish Minister of Energy to drastically cut the financial aid of new PV installations, resulting in strongly reduced levels of $13 \%$ yearly growth in 2012.

In 2011, the total installed PV power in Flanders has reached almost $1.7 \mathrm{GW}$, resulting in a energy production of more than $991 \mathrm{GWh}$ that year [15]. In the first half of 2012, these installations already produced $793 \mathrm{GWh}$ of energy, constituting $33 \%$ of the total renewable energy production in Flanders ${ }^{1}$. The total power of installations is more or less evenly spread between small private installations of less than $10 \mathrm{~kW}$ inverter power $(53,2 \%$ of total installed power) and large industrial installations $(46,8 \%)$. Of the latter, almost two-thirds $(60,1 \%)$ consist of installations with more than $250 \mathrm{~kW}$ power.

After the Flemish budget overrun, the subsidy mechanism for the production of renewable energy was drastically reformed. The financial support provided by the government for new renewable energy installations is now periodically adjusted in function of installation prices and energy prices. The goal of this reformed subsidy mechanism is to establish profitable, but sustainable market conditions for renewable energy production instead of the lucractive situation before.

\footnotetext{
${ }^{1}$ Not including offshore wind energy which is not under Flemish jurisdiction
}

Nonetheless, this radical reform coupled with the repeal of the federal tax breaks and a new feed-in levy imposed by Flemish grid operators has scared away many investors, resulting in the near collapse of the Flemish market for new renewable energy installations in general and new PV systems in particular. New and innovative business approaches will be required in order to still reap sufficient financial benefits of the investments in renewable energy systems in Flanders.

\section{B. Specific yield}

One of the most important parameters in assessing the performance of PV systems is the specific yield, which is defined as the yield of a PV installation in a specific period compared to the total peak power of that same installation and is expressed in $\mathrm{kWh} / \mathrm{kWp}$. In most cases a period of a year is chosen to determine the specific yield. The specific yield allows one to compare the performance of PV plants independent of the size of the plant.

In Flanders a specific yield of $850-950 \mathrm{kWh} / \mathrm{kWp}$ on annual basis is considered conventional. There are some slight variations depending on geography, e.g. the coastal region is less cloudy and therefore has a slightly higher irradation. In this paper a dataset constructed by actual measurements of large PV plants in Flanders is used and shows a specific yield of $992 \mathrm{kWh} / \mathrm{kWp}$.

PV penetration in Flanders is relatively high with on average over $16 \mathrm{PV}$ installations per $\mathrm{km}^{2}$.

\section{Energy sales}

Flemish PV plant operators can sell their generated energy as 'green power' to energy suppliers for slightly better prices than conventional 'grey power'. An inquiry among PV plant operators revealed that green power typical sells for about $€ 43 / \mathrm{MWh}$, while grey power sells for $€ 40 / \mathrm{MWh}$ or less ${ }^{2}$

Green power produced in Flanders was excempt from injection fees levied by distribution system operators (DSO) by a decree issued by the Flemish government, which wanted to support renewable energy production. However recently this decree has been declared void by the Belgian Constitutional Court which ruled that injection fees are a federal jurisdiction and Flemish renewable energy producers should be levied the same taxes as their counterparts in the rest of Belgium. DSOs will now retroactively charge injection fees, however the exact magnitude has yet to be determined.

\section{Subsidy evolution}

Financial support in Flanders for renewable energy systems in general and PV installations in particular is divided over different governmental levels. The most important of these subsidy systems is the so called green power certificate (GPC) system which provides a financial stimulus according to the actual energy production of the PV system. There are some other subsidy systems, e.g. tax breaks provided by the Belgian government for private owners of PV panels and some sector specific financial aids, e.g. the agricultural sector, which will

\footnotetext{
${ }^{2}$ In the period H2 2011-H1 2012.
} 
not be discussed in this paper. Next to these subsidy systems there is of course also the revenue generated by the sale of the generated electricity.

The GPC system awards the owner of the PV plant with a certain grant per MWh of produced energy, which is measured by a certified energy meter. These grants are awarded independently of the plants' size and are guaranteed for a certion period of time. The size and elegibility of the grant depends on the commissioning date of the installation. At the introduction of the GPC system the grant was set at a level of $€ 450 / \mathrm{MWh}$ garuanteed for 20 years, but these figures have recently been drastically cut [14]. The evolution of the grant size and elegibility is shown in table I.

TABLE I: GPC support

\begin{tabular}{|c|c|c|c|}
\hline $\begin{array}{c}\text { Commissioning } \\
\text { date }\end{array}$ & $\begin{array}{c}\text { GPC value } \\
(P \leq 250 \mathrm{~kW})\end{array}$ & $\begin{array}{c}\text { GPC value } \\
(P>250 \mathrm{~kW})\end{array}$ & Elegibility \\
\hline \hline $2006-2009$ & $€ 450$ & $€ 450$ & 20 years \\
\hline 2010 & $€ 350$ & $€ 350$ & 20 years \\
\hline H1 2011 & $€ 330$ & $€ 330$ & 20 years \\
\hline Q3 2011 & $€ 300$ & $€ 240$ & 20 years \\
\hline Q4 2011 & $€ 270$ & $€ 150$ & 20 years \\
\hline Q1 2012 & $€ 250$ & $€ 90$ & 20 years \\
\hline Q2 2012 & $€ 230$ & $€ 90$ & 20 years \\
\hline July 2012 & $€ 210$ & $€ 90$ & 20 years \\
\hline H2 2012 & $€ 90$ & $€ 90$ & 10 years \\
\hline 2013 & $€ 93$ & $€ 93$ & 10 years \\
\hline
\end{tabular}

\section{CVPP POSSIBILITIES}

To determine the feasibility of a CVPP with only solar energy, historical PV energy production data and Belpex trading prices for a period of one year are examined. The PV energy production is based on measurements of actual PV plants in Flanders, the trading prices are provided by Belpex. All datasets comprise the twelve months between 3 November 2011 and 3 November 2012 and contain data with 1 hour interval. With these datasets a 'perfect' CVPP can be simulated, that is to say a CVPP that has $100 \%$ accurate predictions of the day-ahead PV energy generation and without any technical or economical limitations to provide this power to the consumer. This means that all the generated energy is sold at Belpex prices and no injection fees are levied. The size of this simulated CVPP is established at 100MW or around $11 \%$ of the combined power of all Flemish 'large' $(P \geq 10 \mathrm{~kW}) \mathrm{PV}$ plants. In the assumed time period, this virtual plant yielded an energy production of 99,235 MWh. In this section, the comparison will be made between five cases: 1) fixed contract, 2) $100 \%$ accurate predicted production traded at stock prices, 3) stock market trading with $10 \%$ prediction error 4) trading $10 \%$ less than predicted and curtailing excess energy and 5) Use the curtailed energy to supply own controllable loads.

\section{A. Comparison with fixed contract}

Most PV plants operate with a contract which provides a fixed injection fee for the duration of this contract. The average Belpex trading fee during daylight hours for the concerned period amounts to $€ 51,9 / \mathrm{MWh}$. A inquiry among PV plant

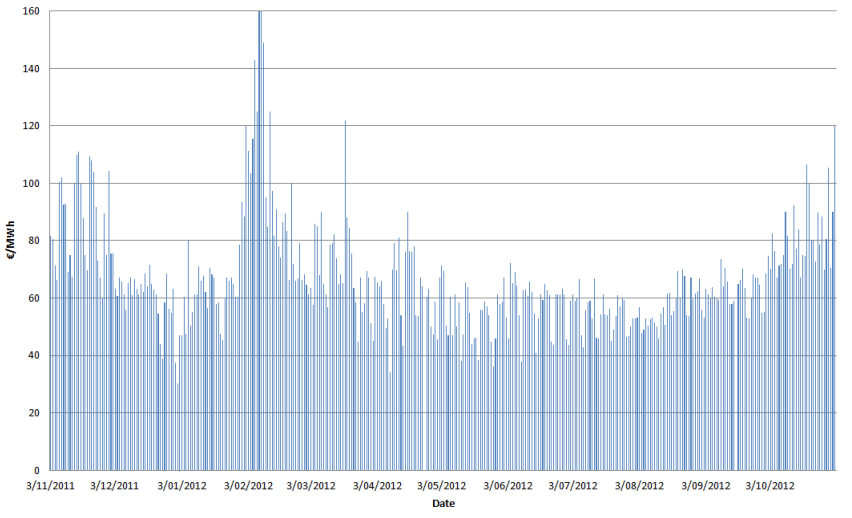

(a) Daily Belpex trading price [€/MWh]

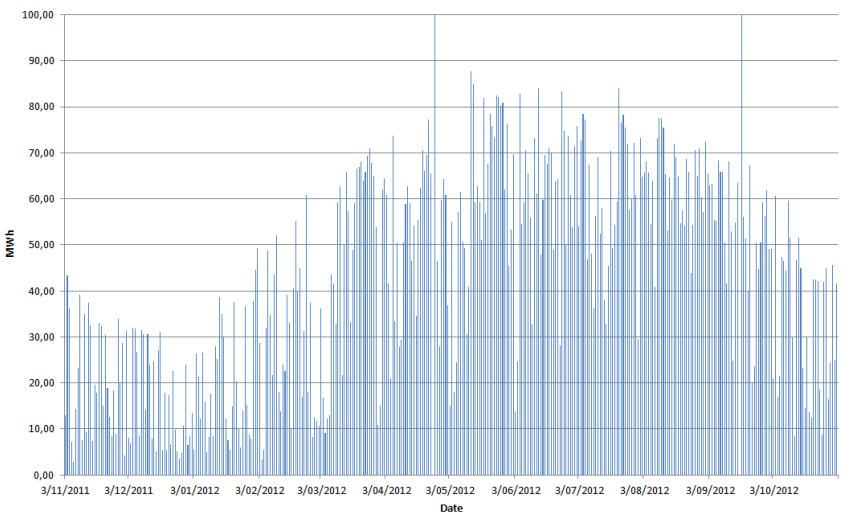

(b) Daily PV energy production [MWh]

Fig. 1: Datasets

owners determined a fixed injection fee of $€ 44 / \mathrm{MWh}$ is a realistic figure for a 1-year contract in the same period. By integrating the daily energy production (fig. $1 b$ ) and associated daily Belpex prices (fig. 1a) for every interval in the dataset, a financial yield of $€ 4,833,635$ is obtained. On the other hand, the conventional fixed contract would have resulted in a financial yield of $€ 4,366,340(99,235 \mathrm{MWh} \times 44 / \mathrm{MWh})$, which is $€ 467,295$ less than in CVPP operation.

In both cases, this revenue is supplemented by $€ 26,793,180$ of GPCs. The sale of generated energy only contributes around $14 \%$ of the total revenue generated by this $100 \mathrm{MW}$ PV plant, and the difference between fixed contract or CVPP operation only amounts to $1,5 \%$.

However, if the CVPP was built in the second half of 2012, when the reformed Flemish subsidy mechanism was put in effect, GPC revenue would fall to $€ 8,931,060$ meaning the share of the sale of energy in the total revenue would rise to $33 \%$. The difference between fixed contract and CVPP operation would now amount to $3,5 \%$. It is clear that the CVPP concept offers some interesting but challenging opportunities.

\section{B. Prediction errors}

The above simulation assumes the ability to predict the dayahead energy production of the CVPP with $100 \%$ accuracy. In reality, several uncertainty factors will influence the exactness of this prediction. The most influential uncertainty factors are meteorological conditions and technical failures. 
If the ARP, in this case the CVPP operator, fails to abide to the specified day-ahead energy production, a penalty fee dependent on the deviation has to be paid to the TSO. This penalty is a compensation for the TSO which is responsible for maintaining the grid balance. The penalty price is fixed every 15 minutes and is dependent on grid conditions and the nature of the ARP inbalance (energy production surplus or deficit).

There is also the possibility to use the intraday market to compensate production deficits by buying surpluses from other ARPs. However, this is considered an exception and ARP's can regulatory only use this option very sparsely, e.g. no more than three consecutive days. With this restriction the TSO wants to limit the speculative trading that might otherwise arise on the intraday market.

If an average day-ahead negative prediction error of $10 \%$ (the plant performs $10 \%$ less than predicted) is assumed, the resulting total penalty fee amounts to $€ 448,833$, reducing the CVPP profit to $€ 18,472$ compared to fixed contract operation.

If positive prediction errors occur (the plant performs better than predicted) it is assumed that the CVPP operator will make a downward adjustment of the power output of the plant so penalty fees for production surplus will be avoided. This way a CVPP operator can build in a safety margin. This also means the GPC revenue will be lower. In this case the CVPP operator will generate a revenue of $€ 28,464,133$ or $€ 2,695,375$ less than on a fixed contract.

\section{Increasing profits}

From the paragraphs above, it is clear that a purely 'injection based' CVPP offers little financial benefits while heavily increasing operator risks. Profits are heavily dependent on the ability to correctly forecast day-ahead energy production and the relative share of energy sales in total plant revenue.

Another way to increase profits is to not only use the CVPP for energy production but also for intelligent load management. This way, the CVPP operator can safely underestimate the day-ahead energy production of the plant and use any excess energy production to supply to local electrical loads. Grid inbalance and the purchase of energy for the loads is avoided, and GPCs are awarded for the actual total energy production. If the CVPP operator underestimates its day-ahead production by $10 \%$ and uses the excess energy to power loads that otherwise would have to purchase energy at Belpex prices, the total revenue becomes $€ 31,658,476$ or $€ 499,967$ more than on a fixed contract.

TABLE II: Comparison of different scenarios

\begin{tabular}{|c|c|c|c|c|c|}
\hline $\begin{array}{c}\text { Prices in } \\
€ 1000\end{array}$ & $\begin{array}{c}\text { Fixed } \\
\text { contract }\end{array}$ & $\begin{array}{c}\text { CVPP } \\
0 \% \text { err. }\end{array}$ & $\begin{array}{c}\text { CVPP } \\
10 \% \text { err. }\end{array}$ & $\begin{array}{c}\text { CVPP } \\
10 \% \text { marg. } \\
10 \% \text { error }\end{array}$ & $\begin{array}{c}\text { CVPP } \\
10 \% \text { err. } \\
\text { consump. }\end{array}$ \\
\hline \hline $\begin{array}{c}\text { Energy } \\
\text { sales }\end{array}$ & $€ 4,366$ & $€ 4,833$ & $€ 4,385$ & $€ 4,350$ & $€ 4,350$ \\
\hline GPC & $€ 26,793$ & $€ 26,793$ & $€ 26,793$ & $€ 24,114$ & $€ 26,793$ \\
\hline $\begin{array}{c}\text { Avoided } \\
\text { purchase }\end{array}$ & & & & & $€ 515$ \\
\hline Total & $€ 31,159$ & $€ 31,626$ & $€ 31,178$ & $€ 28,464$ & $€ 31,658$ \\
\hline Margin & $100 \%$ & $101,5 \%$ & $100,1 \%$ & $91,35 \%$ & $101,6 \%$ \\
\hline
\end{tabular}

\section{CONClusion}

In this paper, the authors discussed the operation of the Belgian energy exchange Belpex and introduced some possibilities on how a Solar Virtual Power Plan could be coupled to this system. Some simplified economic calculations were performed to assess the viability of CVPP and the impact of subsidy schemes and energy cost were analyzed.

The preliminary result is that a plain 'injection based' CVPP offers little to no financial benefits as opposed to conventional fixed contract operation of PV plants. While revenue generated from selling the generated power at the energy exchange is higher, the impact of difficult-to-predict influence factors also increases the risk of penalty fees. However, when the 'injection based' CVPP is supplemented by manageable electrical loads that can sink excess generated power the economic case for a CVPP becomes more convincing.

The authors suggest that additional research is required for two particular topics: the day-ahead prediction accuracy for renewable energy production based meteorological forecasts and the technical possibilities on implementing a VPP with other (manageable) energy production and demand side management. Due to the large inequality between the energy and GPC revenue (tab. I), a close eye must be kept on two factors that will make the VPP concept even more interesting: the rising energy prices and the diminishing subsidy schemes, both of which will open new perspectives for innovative energy production and trading.

\section{ACKNOWLEDGMENT}

The authors would like to thank EFRO and the project partners of project 655 for the funding of the research of B. Zwaenepoel and J. Laveyne, FWO Vlaanderen for the Fellowship of T.L. Vandoorn, and Kevin Gaytant, director of Argus Technologies for providing PV yield and financial data.

\section{REFERENCES}

[1] EPEX, "Epex spot entrance fees," online, April 2012.

[2] Belpex, "Fee, invoicing and vat procedure," online, September 2012.

[3] EPEX, "Epex spot operational rules," online, October 2012.

[4] Belpex, "Market segment procedure," online, October 2011.

[5] M. Sharma, "Flow based market coupling," Master's thesis, Delft University of Technology, 2007.

[6] Elia, Day-Ahead Market Coupling ensuring better market liquidity, May 2012.

[7] - The day-ahead hub: a platform at the centre of ARPs activities, online, Elia, May 2012.

[8] - Nominations: principles and methods, Elia, 2012.

[9] UCTE, "Ucte oh: Policy 1: Load-frequency control - final version," March 2009.

[10] Elia, The balancing mechanism: ensuring the balance of the Elia control area, e1-e-15.02.2012 ed., February 2012.

[11] _ Imbalance tariffs: compensation tariffs as an incentive for ARPS to maintain balance in their balancing perimeter, e2-e-14.02.2012 ed., Elia, February 2012.

[12] — The intraday hub: energy exchanges between ARPs to deal with unforeseen circumstances, e5-e-11.04.2012 ed., April 2012.

[13] Belpex, "Market resilience analysis," APX-Endex, Tech. Rep., 2012.

[14] VREG, Tech. Rep., 2012.

[15] "Halfjaarlijkse statistieken groene stroom," VREG, Tech. Rep., 2012. 